\title{
Thrombomodulin is Associated with Increased Mortality and Organ Failure in Mechanically Ventilated Children with Acute Respiratory Failure: A Prospective Observational Study.
}

Ana C Monteiro ( $\nabla$ acostamonteiro@mednet.ucla.edu )

Ronald Reagan UCLA Medical Center https://orcid.org/0000-0002-1501-4435

Heidi Flori

University of Michigan

Mary K Dahmer

University of Michigan

Myung Shin Sim

University of California Los Angeles

Michael W. Quasney

University of Michigan

Martha A.Q. Curley

University of Pennsylvania

Michael A Matthay

University of California San Francisco

Anil Sapru

University of California Los Angeles https://orcid.org/0000-0003-1528-8249

\section{Research}

Keywords: Acute Respiratory Distress Syndrome, Acute Respiratory Failure, Dead Space Ventilation, Thrombomodulin, coagulation, vascular injury

Posted Date: January 21st, 2021

DOl: https://doi.org/10.21203/rs.3.rs-150966/v1

License: (9) (1) This work is licensed under a Creative Commons Attribution 4.0 International License. Read Full License 
Version of Record: A version of this preprint was published at Critical Care on August 3rd, 2021. See the published version at https://doi.org/10.1186/s13054-021-03626-1. 


\section{Abstract}

\section{BACKGROUND}

Acute respiratory failure (ARF) can progress to acute respiratory distress syndrome (ARDS) and death. Biomarkers such as soluble thrombomodulin (STM), implicated in pulmonary vascular injury, may allow for risk stratification and prognostic enrichment in ARF.

\section{METHODS}

This was a prospective observational study of 432 patients aged 2 weeks - 17 years requiring invasive mechanical ventilation. It was ancillary to the multicenter clinical trial, Randomized Evaluation of Sedation Titration for Respiratory Failure (RESTORE). After consent, patients had up to 3 plasma samples collected at 24-hour intervals within 5 days after intubation. STM was assayed by ELISA. Hazard ratio (HR) for 90-day mortality was determined by cox regression. Mixed effect models (MEM) were used to test for association with extrapulmonary multiorgan failure (MOF) and oxygenation index (OI). Age, race, sex and PRISM-III scores were used as confounding variables for multivariable analyses.

\section{RESULTS}

sTM values ranged from 16.6 to $670.9 \mathrm{ng} / \mathrm{ml}$ within 5 days after intubation. Higher sTM was associated with increased 90-day mortality $(n=432$, adjusted $H R=1.003, p=0.02)$ and worse $\mathrm{Ol}$ in the first 5 days after intubation $(n=252$, Estimate $=0.02, p<0.01)$. Both initial and slope of sTM were associated with increased extrapulmonary MOF in unadjusted and adjusted analyses (Intercept, Estimate $=0.003, p<0.0001$; and slope, Estimate $=0.01, p=0.0009, n=386$ ).

\section{CONCLUSIONS}

Plasma sTM are associated with mortality, severity of ARDS extrapulmonary MOF in children with ARF. This suggests a role of vascular injury in pathogenesis of ARF and provide potential application for targeted therapies.

\section{TRIAL REGISTRATION}

NCT00814099

\section{Background}

Acute respiratory failure (ARF) can progress to pediatric acute respiratory distress syndrome (PARDS), multiorgan failure (MOF) and death.(1-3) The heterogeneity of ARF and PARDS are potential impediments to the discovery of effective therapeutic options,(4) and consequently, recent studies have aimed to endotype, subclassify and prognostically enrich ARDS based on clinical and serum biomarkers. $(5,6)$ In adults, clinical markers such as dead space fraction(7-9) and the ventilatory ratio(10-12) have 
highlighted the contribution of inefficient ventilation in the prognosis of ARDS, and are starting to be used in clinical investigation. Serum biomarkers, by enabling mechanism-specific subclassification of ARDS, may also elucidate pathway-targeted therapies, and enable predictive enrichment.(13) A role for inflammation in pathogenesis of PARDS has been supported by studies showing that plasma levels of interleukins (IL)-6, IL-8, IL-10, IL-18, soluble Tumor Necrosis Factor Receptor-2 and interleukin-1 receptor antagonist(14-16) are associated with higher mortality in these patients. In addition, plasminogen activator inhibitor-1 and soluble thrombomodulin (STM) and von Willebrand factor-antigen, involved in endothelial injury and dysregulated coagulation, are also implicated in pathogenesis of adult(17-19) and pediatric $(20,21)$ ARDS, potentially through microvascular thrombosis contributing to dead space ventilation and organ dysfunction.

Thrombomodulin is an attractive candidate for assessment of ARF and ARDS given that the majority of thrombomodulin is found in the lung(22) and its cleaved, soluble form (sTM) can be detected in patient plasma.(23) Thrombomodulin is an antithrombotic mediator usually expressed as a transmembrane protein in endothelial cells.(23) Additionally, specific gene polymorphisms of thrombomodulin have been associated with increased mortality in adult ARDS.(24) Thrombomodulin is cleaved by matrix metalloproteinases (MMPs) in a pro-inflammatory milieu, and while its soluble form is still an active antithrombotic, its cleavage leads to impaired local avidity and loss of functional activity.(23) As such, elevated levels of plasma sTM reflect inflammation, endothelial damage, and loss of protection against thrombosis. Indeed, a post-hoc analysis of the FACTT trial revealed that elevated levels of plasma sTM were associated with higher mortality in adult patients with ARDS.(19) In addition, we reported preliminary findings that sTM levels are associated with increased mortality in children with ARDS caused by indirect lung injury,(21) though these findings not yet been validated in an independent, heterogenous cohort. A recent systematic review has highlighted the insufficient number of studies evaluating the role of sTM as a predictor of mortality in ARDS.(25) Therefore, as part of the Genetic Variation and Biomarkers in Children with Acute Lung Injury (BALl; R01 HL095410) which enrolled over 500 patients who were part of the Randomized Evaluation of Sedation Titration for Respiratory Failure (RESTORE; U01 HL086622) prospective clinical trial, we tested whether the hypothesis that plasma sTM is a predictor of ARDS severity, mortality and worse outcomes in pediatric patients with acute respiratory failure requiring mechanical ventilation.

\section{Methods}

\section{Patients}

This study, Genetic Variation and Biomarkers in Children with Acute Lung Injury (BALl; R01HL095410), was an ancillary study to the multisite clinical trial, Randomized Evaluation of Sedation Titration for Respiratory Failure (RESTORE; U01 HL086622) that enrolled intubated mechanically ventilated children. (16) Details of the study methodology of have been published previously.(26) and relevant details are summarized in the appendix. 


\section{Measurements}

Blood samples were taken within $24 \mathrm{~h}$ of consent and again 24 and $48 \mathrm{~h}$ later with the first blood sample drawn within three days of intubation (days 0-3) in most patients (98\%). Plasma thrombomodulin levels were measured using two-antibody sandwich enzyme linked immunosorbent assays (ELISA, Asserchrome, Diagnostica Stago). The measurements were carried out in duplicate and followed the manufacturer's protocol. For this study we analyzed up to three sTM measurements per patient, collected within the first 5 days after intubation.

\section{Primary outcomes}

We examined the association between plasma sTM and 90-day in-hospital mortality adjusted for confounding variables.

\section{Secondary Outcomes}

We examined the association of sTM with OI, PARDS diagnosis, the presence of non-pulmonary organ failure, duration of mechanical ventilation, and PICU length of stay in survivors. The determination of secondary outcomes is described in the supplement.

\section{Confounding variables}

Analysis was adjusted for age, race, sex and PRISM-III scores by multivariable analyses. These confounders were chosen a priori for their clinical significance and face validity. We used PRISM-III to adjust for baseline severity of illness.

\section{Statistics}

Given the unique nature of our dataset, which included repeated measurements of sTM along several days, and outcomes that ranged from continuous to binary outcomes with time varying covariates, we tested the relationship between STM and primary and secondary outcomes using multiple approaches. We calculated odds ratio (OR) of mortality (alive or deceased at 90 days) given daily sTM level for days 02. Receiver operating characteristic (ROC) curves were then used to assess whether sTM drawn on these days could predict mortality. We also analysed the relationship of STM with mortality utilizing a composite estimate of all sTM levels in an individual patient using sTM intercept and slope as detailed in the supplement. Finally the hazard ratio (HR) for 90 day in-hospital mortality was assessed from sTM of all patient plasma samples collected between the day of intubation (day 0 ) and day 5 using counting process cox proportional hazard analysis.(27)

STM values on individual days up to day 3 were compared by Mann Whitney $U$ test between patients with PARDS and those without (days 4 and 5 were excluded due to low numbers). HR for PARDS onset was determined from all sTM samples collected from an individual patient between the day of intubation 
(day 0) and day 5 (or the day PARDS developed, whichever came first) using counting process cox proportional hazard analysis.

Mixed effect modelling (MEM) was used to test the relationship of STM with MOF, PICU length of stay, and days on ventilator. MEM was also used to evaluate the relationship between the initial STM (intercept) or the rate of increase of STM (slope) and maximum OI. Daily Ols (or if unavailable, converted OSIs) up until maximum value were analyzed using mixed effect modelling (MEM), with sTM intercepts and slopes as predictor variables and age, gender, race/ethnicity and PRISM-III score as confounding variables. The relationship between initial sTM or rate of change of STM and daily number of failed organs within the first 28 days was also evaluated using MEM.

\section{Study Approval}

Written informed consent was obtained from patients on their guardians prior to inclusion in the study. The study was approved by the Institutional Review Boards at all participating sites.

\section{Results}

\section{Study Population}

549 patients were enrolled in the BAL/ study with 480 having plasma samples. Of those, 432 had at least one sample assayed for sTM within 5 days of intubation (day 0) (Figure S1). These patients formed the population for this study. Clinical characteristics of the entire $B A L /$ cohort as well as those with and without PARDS have been described previously.(15) Clinical characteristics of the population for this study is shown in Table S1. Mortality in the BAL/cohort was $9 \%$, with a median duration of mechanical ventilation of 7.1 days (IQR, 4.0-13.6) and a median PICU length of stay in survivors of 10.6 days (IQR, 6.6-18.4).(16) The main primary cause of death was respiratory failure (17 patients, $4 \%$ ), followed by multi organ failure (10 patients, $2.3 \%$ ), as listed in Table S2.

\section{Plasma Soluble Thrombomodulin Increases with Time}

Up to three measurements of daily STM were obtained within the first 5 days of the study for 432 patients (Figure S1). The median daily sTM demonstrated an upward trend up to day three (Figure 1). The distribution of STM on individual days was not statistically different between patients with or without PARDS (unadjusted, Figure S2). The wide standard deviation for STM was partly attributed to the inherent heterogeneity of the study population. As such, multivariate analyses were utilized to adjust for the effects of age, race and severity of illness.

\section{Soluble Thrombomodulin is predictive of increased mortality in ventilated pediatric patients}

We performed univariate analysis using STM as the predictor variable with mortality as the outcome and multivariable analysis incorporating age, PRISM-III score, race (Caucasian vs. not) and sex as covariates. Univariate, logistic regression analysis on individual days revealed that STM measured at days 1 and 2 
were associated with higher OR for mortality (Day 1, OR= 1.005 per unit increase in sTM, Cl= 1.001-1.008, $\mathrm{n}=233$ and Day 2, OR= 1.004 per unit increase in sTM, Cl=1.002-1.007, n= 321, data not shown).

Multivariable analysis of individual days revealed that STM levels adjusted for selected covariates and measured at days 1 and 2 were associated with higher OR for mortality (1.01, p=0.02 for day 1, Table 1, and $\mathrm{p}<0.01$ for day 2 , data not shown). Receiver-operating characteristic (ROC) curve for the univariate analysis of STM and mortality revealed an area under the curve (AUC) of 0.70 for thrombomodulin at day 1 (Figure 2) and an AUC of 0.63 for day 2 (data not shown). Given the higher AUC, we evaluated whether a certain threshold value of sTM was most useful for predicting mortality at day 1 . At day 1 , the cut off level of sTM level based on ROC would be $130 \mathrm{ng} / \mathrm{ml}$, which in this cohort provided a specificity of $69 \%$ and a sensitivity of $67 \%$ for predicting mortality. Additionally, at day 1, a cut off sTM level of $185 \mathrm{ng} / \mathrm{ml}$ would provide a specificity of $90 \%$ however a sensitivity of only $33 \%$ for predicting mortality in this population, as assessed by ROC (Figure 2), Conversely, a sTM cut-off value of $80 \mathrm{ng} / \mathrm{ml}$ would confer a sensitivity of $89 \%$ and a specificity of $31 \%$. We finally asked whether sTM obtained within the first 5 days of intubation was associated with in-hospital 90-day mortality. Using

cox-regression, in both univariate and multivariable models, sTM had a statistically significant association with mortality. For univariate analysis, the HR was 1.003 (IQR 1.001-1.005, p<0.002) and for multivariable analysis, HR was 1.003 (IQR 1.00-1.005, $p=0.02$ ) for each nanogram/milliliter increase in measured STM (Table 2). These data suggest that elevated levels of sTM, and specifically levels measured on day 1, correlate with increased odds of in-hospital mortality.

\section{Levels of Soluble Thrombomodulin correlate with presence of multi-organ failure.}

Next, we asked if sTM levels obtained within 5 days of intubation were associated with increased number of non-pulmonary failed organs up to hospital day 28. Out of the 432 patients with sTM collected within 5 days of intubation, 45\% (194) experienced non pulmonary multiorgan failure (2 or more failed organs in addition to the need for ventilation). To evaluate for number of failed organs as an outcome, the rate of change of sTM (slope) and projected sTM at day 0 (intercept) were used as the predictor variables. A multivariable MEM adjusting for age, sex, race (Caucasian vs not), and PRISM-III score revealed that higher starting values of sTM as well as the rate of increase of sTM (i.e., intercept and slope), were associated with an increased number of extrapulmonary failed organs daily up to day 28 (For sTM intercept, Estimate=0.003, $p<0.0001$; For sTM slope, Estimate=0.01, $p=0.0009, n=386$, Table 3).

\section{Soluble Thrombomodulin did not correlate with onset of pediatric ARDS, days on mechanical ventilation or ICU length of stay.}

Of the 178 patients who had plasma collected within the first five days who did not already have PARDS on day of intubation, 53 developed PARDS on day 1 or later; of those, 29 also had sTM collected on or before day of onset of PARDS. We evaluated whether STM values of patients who did not already have PARDS on day 0 were associated with PARDS development using counting process cox regression. There was no statistically significant correlation between a patient's collected STM values and development of PARDS (data not shown). We next evaluated if sTM levels correlated with length of stay (LOS) in the 
pediatric ICU (PICU) or days of mechanical ventilation. MEM revealed that neither increased slope of sTM nor the sTM intercept (i.e., initial STM) incurred a statistically significant association with PICU LOS ( $p>0.4$ for sTM slope and intercept, $n=430$, data not shown) or with days on mechanical ventilation ( $p>0.4$ for slope and intercept, $n=430$, data not shown).

\section{Levels of soluble Thrombomodulin correlate with worsening oxygenation}

We tested the relationship of STM measured within the first 5 days after intubation with maximum OI values measured or calculated using OSI within those 5 days. Only STM values collected before the peak Ol was reached were utilized for this analysis. A unit increase in STM $(1 \mathrm{ng} / \mathrm{ml})$ was associated with a statistically significant increase in OI (Table 4, estimate $=0.015, p=0.01, n=252$ ) after adjusting for age, sex, PRISM-III score and race (Caucasian vs. not). Levels of sTM examined on individual days revealed no statistically significant association with maximal OI (data not shown).

\section{Discussion}

In this study, higher initial values and rates of increase in soluble thrombomodulin (sTM) were associated with mortality in children with ARF. There was also a statistically significant association between STM and oxygenation index, a validated marker of pulmonary dysfunction and ARDS severity. $(28,29)$ Finally, the higher initial values of sTM, and/or a greater rate of increase of STM, were associated with multiorgan failure.

These findings corroborate prior studies that revealed an association between organ failure and STM in children and adults with ARDS, as well as an association of STM with mortality in children with indirect lung injury as well as among adults with ARDS from any cause. $(21,30)$ Thus, the pathogenetic and prognostic value of soluble thrombomodulin is supported by several clinically relevant studies.

STM is an attractive candidate biological marker for respiratory failure and ARDS because thrombomodulin, an anti-thrombotic agent found in the endothelial cell surface, is cleaved into its soluble form in response to local endothelial damage.(23) Interestingly, both full length and the soluble form of thrombomodulin are protective against thrombosis. However once thrombomodulin is cleaved and released into the circulation, it is assumed that the local anti-thrombotic effect is lost due to reduced avidity of the marker caused by its cleavage, generation of fragments of varying lengths and affinities and whole-body redistribution. While it is likely that STM levels increase in response to endothelial damage in a variety of organs, thrombomodulin is most prominently expressed in the human lung.(22) . Thrombomodulin also plays an important role in lung development,(31) which may imply a higher concentration of STM in the pediatric lung, but this is not known. Regardless, it is likely that pulmonary vascular damage would be a principal contributor to serum STM in this study of pediatric acute respiratory failure from primary pulmonary or airways disease. Given the known association of sTM with vascular damage, and the loss of the anti-thrombotic molecule at the site of injury, it is conceivable that elevated sTM may contribute to an increase in pulmonary dead space ventilation in ARDS. Dead space is a strong predictor of mortality in ARDS, even surpassing markers that measure oxygenation such as OI 
and P/F ratio. $(8,9,32)$ Since the RESTORE trial did not record parameters for dead space ventilation, future studies on STM would benefit from a prospective evaluation of STM and dead space ventilation in ARDS or ARF.

Recombinant sTM, by replacing the vasculitis-induced depletion of membrane-bound local thrombomodulin, has been implicated in protection or reversal of vascular injury, disseminated intravascular coagulation (DIC) and in animal models of ARDS. In animal studies, recombinant sTM was shown to have a protective effect on septic rats by suppressing leukocyte adhesion to the microvasculature, reducing thrombus formation, and preventing endothelial damage;(33) and murine studies have suggested a protective role of STM in LPS-induced ARDS.(34) In humans, a randomized clinical trial evaluating patients with DIC suggested that treatment with recombinant sTM showed a more significant reversal of DIC than did heparin therapy, but did not evaluate the outcome of mortality.(35) However, a large, multicenter clinical trial testing the therapeutic effect of recombinant STM on 800 patients with sepsis-associated coagulopathy revealed no effect of sTM therapy on patient mortality, or secondary outcomes such as shock free, dialysis free and ventilator free days.(36) Since the latter study enrolled patients presenting with sepsis complicated by DIC, it is very possible that the population was too heterogenous to observe an effect on patients that would otherwise benefit from therapy. There was no effort in that trial to enrich for patients with an elevated thrombomodulin plasma level. In contrast, the $B A L /$ cohort, in which we did find an association of elevated levels of STM with higher mortality, included only children with a primary respiratory diagnosis. We postulate that since sTM is primarily derived from lung endothelium, patients with respiratory failure may be more likely to show a benefit from recombinant thrombomodulin compared to a population with non-pulmonary sources of sepsis. In addition, given the promising therapeutic effect of recombinant STM on murine ARDs, it would be important to evaluate the therapeutic role of recombinant thrombomodulin specifically in patients with ARDS demonstrating elevated dead space ventilation and increased STM as a marker of thrombomodulin depletion from the pulmonary vascular endothelium. Dead space could be measured at the bedside with the ventilatory ratio, an index that is associated with higher mortality in ARDS.(10)

The strength of this study lies in its relatively large sample size that includes a diverse study population in children. In addition, the study benefits from the availability of plasma samples from multiple time points and a well curated collection of data elements. The chosen outcomes of mortality, PARDS severity and multi-organ failure are of high clinical applicability and are arguably the most useful in assessing patient health. One study limitation is that all outcomes studied were measured in a population with some subtype of respiratory failure as a primary diagnosis, with almost $70 \%$ of the cohort developing PARDS within 5 days of intubation. As such, these findings can only be interpreted in the context of respiratory failure commonly leading to PARDS. Another limitation is that since over $90 \%$ of patients who developed PARDS did so by day 1 , there was limited opportunity to assess the association of STM with PARDS development.

\section{Conclusion}


Plasma levels of sTM in pediatric patients receiving ventilatory support were predictive of worsening oxygenation defect, higher mortality and more organ failure. Consequently, sTM may have clinical promise in biomarker guided therapies. Future studies are needed to evaluate whether sTM correlates with worsening dead space ventilation and whether dead space could be reversed in select patients with ARF treated with sTM.

\section{Declarations}

\section{Ethics Approval and Consent to Participate}

Written informed consent was obtained from patients on their guardians prior to inclusion in the study. The study was approved by the Institutional Review Boards at all participating sites.

\section{Consent for Publication}

Not Applicable

\section{Availability of data and materials}

The data that support the findings of this study are available from the RESTORE study but restrictions apply to the availability of these data, which were used under license for the current study, and so are not publicly available. Data are however available from the authors upon reasonable request and with permission of the RESTORE study.

\section{Competing interests}

The authors have declared that they have no conflict of interest exists.

\section{Funding}

R01HL095410 awarded to Drs. Sapru, Dahmer, Flori and Quasney, HL123004, HL140026 awarded to Dr. Matthay, 2T32HL072752-16 awarded to Dr. Monteiro, and R01 HL0114484 awarded to Dr. Sapru. The parent study was supported by grants from the NIH awarded to Drs. Curley and Wypij (U01HL086622, U01 HL086649).

\section{Author contributions}

ACCM wrote the manuscript and analyzed the data, HF, MKD and AS conceptualized the study, collected the data and performed significant editing of the manuscript, MSS performed the statistical analysis, MWQ, MAQC conceptualized the parent study and performed significant editing of the manuscript, MAM performed significant editing of the manuscript.

\section{Acknowledgments}


We would like to thank all the patients and guardians of those patients for their participation in the study. We would also like to acknowledge the contribution of the BALI study investigators at the sites that participated in the RESTORE study including: Scot T. Bateman (University of Massachusetts Memorial Children's Medical Center, Worcester, MA), M. D. Berg (University of Arizona Medical Center, Tucson, AZ), Santiago Borasino (Children's Hospital of Alabama, Birmingham, AL), G. Kris Bysani (Medical City Children's Hospital, Dallas, TX), Allison S. Cowl (Connecticut Children's Medical Center, Hartford, CT), Cindy Darnell Bowens (Children's Medical Center of Dallas, Dallas, TX), E. Vincent S. Faustino (Yale-New Haven Children's Hospital, New Haven, CT), Lori D. Fineman (University of California San Francisco Benioff Children's Hospital at San Francisco, San Francisco, CA), A. J. Godshall (Florida Hospital for Children, Orlando, FL), Ellie Hirshberg (Primary Children's Medical Center, Salt Lake City, UT), Aileen L. Kirby (Oregon Health \& Science University Doernbecher Children's Hospital, Portland, OR), Gwenn E. McLaughlin (Holtz Children's Hospital, Jackson Health System, Miami,FL), Shivanand Medar (Cohen Children's Medical Center of New York, Hyde Park, NY), Phineas P. Oren (St. Louis Children's Hospital, St. Louis, MO), James B. Schneider (Cohen Children's Medical Center of New York, Hyde Park, NY), Adam J. Schwarz (Children's Hospital of Orange County, Orange, CA), Thomas P. Shanley (C. S. Mott Children's Hospital at the University of Michigan, Ann Arbor, MI), Lauren R. Sorce (Ann \& Robert H. Lurie, Children's Hospital of Chicago, Chicago, IL), Edward J. Truemper (Children's Hospital and Medical Center, Omaha, $\mathrm{NE}$ ), Michele A. Vander Heyden (Children's Hospital at Dartmouth, Dartmouth, NH), Kim Wittmayer (Advocate Hope Children's Hospital, IL), Athena Zuppa (Children's Hospital of Philadelphia, Philadelphia, PA) and the RESTORE data coordination center led by David Wypij, PhD (Department of Biostatistics, Harvard School of Public Health, Boston, Massachusetts; Department of Pediatrics, Harvard Medical School, Boston, Massachusetts; Department of Cardiology, Boston Children's Hospital, Boston, Massachusetts).

\section{References}

1. Quasney MW, López-Fernández YM, Santschi M, Watson RS. The Outcomes of Children With Pediatric Acute Respiratory Distress Syndrome. Pediatr Crit Care Med [Internet]. 2015 Jun [cited 2020 May 21];16:S118-31. Available from: http://content.wkhealth.com/linkback/openurl? sid=WKPTLP:landingpage \&an=00130478-201506001-00011

2. Barreira ER, Munoz GOC, Cavalheiro PO, Suzuki AS, Degaspare N V., Shieh HH, et al. Epidemiology and Outcomes of Acute Respiratory Distress Syndrome in Children According to the Berlin Definition. Crit Care Med [Internet]. 2015 May [cited 2020 May 21];43(5):947-53. Available from: http://journals.Iww.com/00003246-201505000-00004

3. Khemani RG, Smith L, Lopez-Fernandez YM, Kwok J, Morzov R, Klein MJ, et al. Paediatric acute respiratory distress syndrome incidence and epidemiology (PARDIE): an international, observational study. Lancet Respir Med [Internet]. 2019 Feb 1 [cited 2019 Dec 27];7(2):115-28. Available from: http://www.ncbi.nlm.nih.gov/pubmed/30361119

4. Matthay MA, Liu KD. New Strategies for Effective Therapeutics in Critically III Patients. JAMA [Internet]. 2016 Feb 23 [cited 2020 Apr 21];315(8):747. Available from: 
http://jama.jamanetwork.com/article.aspx?doi=10.1001/jama.2016.0661

5. Calfee CS, Meyer NJ. Novel translational approaches to the search for precision therapies for acute respiratory distress syndrome [Internet]. Vol. 5, Lancet Respir Med. 2017 [cited 2020 Apr 21]. Available from: www.thelancet.com/respiratory

6. Yehya N. Pediatric ARDS biomarkers: missing the random forest for the trees. Crit Care [Internet]. 2019 Dec 25 [cited 2021 Jan 14];23(1):97. Available from: https://ccforum.biomedcentral.com/articles/10.1186/s13054-019-2396-7

7. Nuckton TJ, Alonso JA, Kallet RH, Daniel BM, Pittet J-F, Eisner MD, et al. Pulmonary Dead-Space Fraction as a Risk Factor for Death in the Acute Respiratory Distress Syndrome. N Engl J Med [Internet]. 2002 Apr 25 [cited 2019 Aug 14];346(17):1281-6. Available from: http://www.nejm.org/doi/abs/10.1056/NEJMoa012835

8. Kallet RH, Alonso JA, Pittet J-F, Matthay MA. Prognostic value of the pulmonary dead-space fraction during the first 6 days of acute respiratory distress syndrome. Respir Care [Internet]. 2004 Sep 1 [cited 2019 Aug 14];49(9):1008-14. Available from: http://www.ncbi.nlm.nih.gov/pubmed/15329171

9. Kallet RH, Zhuo H, Liu KD, Calfee CS, Matthay MA, National Heart Lung and Blood Institute ARDS Network Investigators. The association between physiologic dead-space fraction and mortality in subjects with ARDS enrolled in a prospective multi-center clinical trial. Respir Care [Internet]. 2014 Nov [cited 2019 Aug 14];59(11):1611-8. Available from:

http://www.ncbi.nlm.nih.gov/pubmed/24381187

10. Sinha P, Fauvel NJ, Singh P, Soni N. Analysis of ventilatory ratio as a novel method to monitor ventilatory adequacy at the bedside. Crit Care [Internet]. 2013 Feb 27 [cited 2019 Aug 14];17(1):R34. Available from: http://www.ncbi.nlm.nih.gov/pubmed/23445563

11. Sinha P, Calfee CS, Beitler JR, Soni N, Ho K, Matthay MA, et al. Physiologic analysis and clinical performance of the ventilatory ratio in acute respiratory distress syndrome. Am J Respir Crit Care Med. 2019;

12. Sinha $\mathrm{P}$, Fauvel NJ, Singh S, Soni N. Ventilatory ratio: a simple bedside measure of ventilation. $\mathrm{Br} \mathrm{J}$ Anaesth [Internet]. 2009 May 1 [cited 2019 Aug 14];102(5):692-7. Available from: http://www.ncbi.nlm.nih.gov/pubmed/19346233

13. Wilson JG, Calfee CS. ARDS Subphenotypes: Understanding a Heterogeneous Syndrome. Crit Care [Internet]. 2020 Dec 24 [cited 2021 Jan 14];24(1):102. Available from: https://ccforum.biomedcentral.com/articles/10.1186/s13054-020-2778-x

14. Zinter MS, Orwoll BE, Spicer AC, Alkhouli MF, Calfee CS, Matthay MA, et al. Incorporating inflammation into mortality risk in pediatric acute respiratory distress syndrome. Crit Care Med. 2017;45(5):858-66.

15. Dahmer MK, Quasney MW, Sapru A, Gildengorin G, Curley MAQ, Matthay MA, et al. Interleukin-1 Receptor Antagonist Is Associated With Pediatric Acute Respiratory Distress Syndrome and Worse Outcomes in Children With Acute Respiratory Failure. Pediatr Crit Care Med [Internet]. 2018 [cited 2019 Oct 12];19(10):930-8. Available from: http://www.ncbi.nlm.nih.gov/pubmed/30095747 
16. Flori H, Sapru A, Quasney MW, Gildengorin G, Curley MAQ, Matthay MA, et al. A prospective investigation of interleukin-8 levels in pediatric acute respiratory failure and acute respiratory distress syndrome. Crit Care [Internet]. 2019 Dec 17 [cited 2019 Oct 9];23(1):128. Available from: http://www.ncbi.nlm.nih.gov/pubmed/30995942

17. Rubin DB, Wiener-Kronish JP, Murray JF, Green DR, Turner J, Luce JM, et al. Elevated von Willebrand factor antigen is an early plasma predictor of acute lung injury in nonpulmonary sepsis syndrome. $J$ Clin Invest [Internet]. 1990 Aug 1 [cited 2020 Dec 4];86(2):474-80. Available from: http://www.ncbi.nlm.nih.gov/pubmed/2384595

18. Ware LB, Matthay MA, Parsons PE, Thompson BT, Januzzi JL, Eisner MD, et al. Pathogenetic and prognostic significance of altered coagulation and fibrinolysis in acute lung injury/acute respiratory distress syndrome. Crit Care Med [Internet]. 2007 Aug [cited 2020 Apr 8];35(8):1821-8. Available from: http://www.ncbi.nlm.nih.gov/pubmed/17667242

19. Sapru A, Calfee CS, Liu KD, Kangelaris K, Hansen H, Pawlikowska L, et al. Plasma soluble thrombomodulin levels are associated with mortality in the acute respiratory distress syndrome. Intensive Care Med [Internet]. 2015 Mar [cited 2019 Nov 19];41(3):470-8. Available from: http://www.ncbi.nlm.nih.gov/pubmed/25643902

20. Sapru A, Curley MAQ, Brady S, Matthay MA, Flori H. Elevated PAI-1 is associated with poor clinical outcomes in pediatric patients with acute lung injury. Intensive Care Med [Internet]. 2010 Jan [cited 2019 Oct 12];36(1):157-63. Available from: http://www.ncbi.nlm.nih.gov/pubmed/19855955

21. Orwoll BE, Spicer AC, Zinter MS, Alkhouli MF, Khemani RG, Flori HR, et al. Elevated soluble thrombomodulin is associated with organ failure and mortality in children with acute respiratory distress syndrome (ARDS): a prospective observational cohort study. Crit Care [Internet]. 2015 Dec 14 [cited 2019 Oct 12];19(1):435. Available from: http://www.ncbi.nlm.nih.gov/pubmed/26652251

22. Su Al, Wiltshire T, Batalov S, Lapp H, Ching KA, Block D, et al. A gene atlas of the mouse and human protein-encoding transcriptomes. Proc Natl Acad Sci U S A [Internet]. 2004 Apr 20 [cited 2019 Dec 27];101(16):6062-7. Available from: http://www.ncbi.nlm.nih.gov/pubmed/15075390

23. Martin FA, Murphy RP, Cummins PM. Thrombomodulin and the vascular endothelium: insights into functional, regulatory, and therapeutic aspects. Am J Physiol Circ Physiol [Internet]. 2013 Jun 15 [cited 2019 Dec 13];304(12):H1585-97. Available from:

https://www.physiology.org/doi/10.1152/ajpheart.00096.2013

24. Sapru A, Liu KD, Wiemels J, Hansen H, Pawlikowska L, Poon A, et al. Association of common genetic variation in the protein $\mathrm{C}$ pathway genes with clinical outcomes in acute respiratory distress syndrome. Crit Care [Internet]. 2016 Dec 23 [cited 2021 Jan 14];20(1):151. Available from: https://ccforum.biomedcentral.com/articles/10.1186/s13054-016-1330-5

25. van der Zee P, Rietdijk W, Somhorst P, Endeman H, Gommers D. A systematic review of biomarkers multivariately associated with acute respiratory distress syndrome development and mortality. Crit Care [Internet]. 2020 Dec 24 [cited 2021 Jan 14];24(1):243. Available from: https://ccforum.biomedcentral.com/articles/10.1186/s13054-020-02913-7 
26. Curley MAQ, Wypij D, Watson RS, Grant MJC, Asaro LA, Cheifetz IM, et al. Protocolized Sedation vs Usual Care in Pediatric Patients Mechanically Ventilated for Acute Respiratory Failure. JAMA [Internet]. 2015 Jan 27 [cited 2019 Dec 27];313(4):379. Available from: http://jama.jamanetwork.com/article.aspx?doi=10.1001/jama.2014.18399

27. Therneau TM, Grambsch PM. Modeling survival data: extending the cox model. Dietz K, Gail M, Krickeberg K, Samet J, Tsiatis A, editors. New York: Springer; 2000.

28. The National Heart, Lung and BIARDS (ARDS) CTN. Comparison of Two Fluid-Management Strategies in Acute Lung Injury. Wiederman, HP; Wheel AP; Bernard GR; Thompson, BT; Hayden, D; deBoisblanc, B; Connors, AF; Hite, RD; Harabin, AL; NHLBI ARDS Clin Trial Network [Internet]. 2006 Jun 15 [cited 2019 Aug 14];354(24):2564-75. Available from: http://www.nejm.org/doi/abs/10.1056/NEJMoa062200

29. Seeley E, McAuley DF, Eisner M, Miletin M, Matthay MA, Kallet RH. Predictors of mortality in acute lung injury during the era of lung protective ventilation. Thorax [Internet]. 2008 Nov 1 [cited 2020 Dec 4];63(11):994-8. Available from: http://www.ncbi.nlm.nih.gov/pubmed/18566110

30. Sapru A, Calfee CS, Liu KD, Kangelaris K, Hansen H, Pawlikowska L, et al. Plasma soluble thrombomodulin levels are associated with mortality in the acute respiratory distress syndrome. Intensive Care Med. 2015;41(3):470-8.

31. Buck CA, Edelman JM, Buck CE, Kennedy G, Scott Baldwin H. Expression Patterns of Adhesion Receptors in the Developing Mouse Lung: Functional Implications. Cell Adhes Commun [Internet]. 1996 [cited 2021 Jan 13];4(2):69-87. Available from: https://www.tandfonline.com/action/journallnformation?journalCode=icac20

32. Kallet RH, Zhuo H, Ho K, Lipnick MS, Gomez A, Matthay MA. Lung Injury Etiology and Other Factors Influencing the Relationship Between Dead-Space Fraction and Mortality in ARDS. Respir Care [Internet]. 2017 Oct 1 [cited 2019 Aug 14];62(10):1241-8. Available from:

http://www.ncbi.nlm.nih.gov/pubmed/28611227

33. Iba T, Aihara K, Watanabe S, Yanagawa $Y$, Takemoto $M$, Yamada A, et al. Recombinant thrombomodulin improves the visceral microcirculation by attenuating the leukocyte-endothelial interaction in a rat LPS model. Thromb Res [Internet]. 2013 Apr 1 [cited 2019 Dec 27];131(4):295-9. Available from: http://www.ncbi.nlm.nih.gov/pubmed/23273403

34. Kudo D, Toyama M, Aoyagi T, Akahori Y, Yamamoto H, Ishii K, et al. Involvement of high mobility group box 1 and the therapeutic effect of recombinant thrombomodulin in a mouse model of severe acute respiratory distress syndrome. Clin Exp Immunol [Internet]. 2013;173(2):276-87. Available from: http://doi.wiley.com/10.1111/cei.12106

35. Saito H, Maruyama I, Shimazaki S, Yamamoto Y, Aikawa N, Ohno R, et al. Efficacy and safety of recombinant human soluble thrombomodulin (ART-123) in disseminated intravascular coagulation: Results of a phase III, randomized, double-blind clinical trial. J Thromb Haemost [Internet]. 2007;5(1):31-41. Available from: http://doi.wiley.com/10.1111/j.1538-7836.2006.02267.x 
36. Vincent J-L, Francois B, Zabolotskikh I, Daga MK, Lascarrou J-B, Kirov MY, et al. Effect of a Recombinant Human Soluble Thrombomodulin on Mortality in Patients With Sepsis-Associated Coagulopathy. JAMA [Internet]. 2019 May 28 [cited 2019 Dec 11];321(20):1993. Available from: http://jama.jamanetwork.com/article.aspx?doi=10.1001/jama.2019.5358

\section{Tables}

Table 1. Soluble Thrombomodulin from Day 1 predicts Mortality.

\begin{tabular}{|lll|}
\hline Covariates & OR $(95 \% \mathrm{Cl})$ & P Value \\
\hline sTM day 1 & $1.01(1.00-1.01)$ & 0.02 \\
\hline Age (Years) & $1.12(1.02-1.22)$ & 0.02 \\
\hline Sex (Male) & $1.46(0.53-4.05)$ & 0.46 \\
\hline Race (White v not) & $1.12(0.33-3.78)$ & 0.86 \\
\hline PRISM-III Score & $1.04(0.98-1.12)$ & 0.25 \\
\hline
\end{tabular}

Multivariable logistic regression analysis of the Odds Ratio of Mortality based on selected covariates. sTM from day 1 was the selected predictor variable. $n=233$.

Table 2. Time dependent multivariate analysis for mortality.

\begin{tabular}{|lll|}
\hline Covariates & HR $(95 \% \mathrm{Cl})$ & P Value \\
\hline sTM & $1.00(1-1.01)$ & 0.02 \\
\hline Age (Years) & $1.09(1.03-1.15)$ & $<0.001$ \\
\hline Sex (Male) & $0.85(0.43-1.662)$ & 0.63 \\
\hline Race (White v not) & $0.64(0.30-1.38)$ & 0.25 \\
\hline PRISM-III Score & $1.02(0.98-1.07)$ & 0.30 \\
\hline
\end{tabular}

Counting process Cox regression analyses were done. STM between days 0 and 5 were used as the selected predictor variable. Selected covariates as listed. The outcome is death. $n=432$

Table 3. Multivariable mixed effect analysis of increase in number of failed organs in the first 28 days. 


\begin{tabular}{|llll|}
\hline Covariates & Estimate & SE & P Value \\
\hline Intercept sTM & $2.77 \mathrm{E}-3$ & $5.21 \mathrm{E}-4$ & $<1.00 \mathrm{E}-4$ \\
\hline Slope sTM & $1.00 \mathrm{E}-2$ & $3.01 \mathrm{E}-3$ & $9.00 \mathrm{E}-4$ \\
\hline Age (years) & $2.96 \mathrm{E}-2$ & $6.40 \mathrm{E}-3$ & $<1.00 \mathrm{E}-4$ \\
\hline Sex (male v not) & $4.80 \mathrm{E}-2$ & $7.37 \mathrm{E}-2$ & 0.51 \\
\hline Race (white v not) & $7.15 \mathrm{E}-3$ & $8.50 \mathrm{E}-2$ & 0.93 \\
\hline PRISM-III Score & $6.03 \mathrm{E}-2$ & $5.35 \mathrm{E}-3$ & $<1.00 \mathrm{E}-4$ \\
\hline
\end{tabular}

Slope of sTM was derived from up to three values of sTM collected within 5 days of enrollment for each patient. Intercept of sTM was derived from the slope. Patients with only one measurement of sTM were excluded. SE- Standard Error. $\mathrm{n}=386$.

Table 4. Estimate of effect of sTM on OI/OSI in the first 5 days.

\begin{tabular}{|llll|}
\hline Covariates & Estimate & SE & P value \\
\hline sTM & $1.51 \mathrm{E}-2$ & $5.53 \mathrm{E}-3$ & 0.01 \\
\hline Age (years) & $-1.77 \mathrm{E}-1$ & $1.06 \mathrm{E}-1$ & 0.10 \\
\hline Sex (male) & -1.25 & 1.22 & 0.31 \\
\hline Race (White v not) & $4.53 \mathrm{E}-1$ & 1.37 & 0.74 \\
\hline Prism III Score & $1.46 \mathrm{E}-1$ & $8.58 \mathrm{E}-2$ & 0.09 \\
\hline
\end{tabular}

Multivariable mixed effect model to estimate effect of sTM on OI/OSI in the first 5 days, adjusted for the covariates of age, gender, race and PRISM-III score. sTM was the selected predictor variable. $n=252$.

\section{Figures}




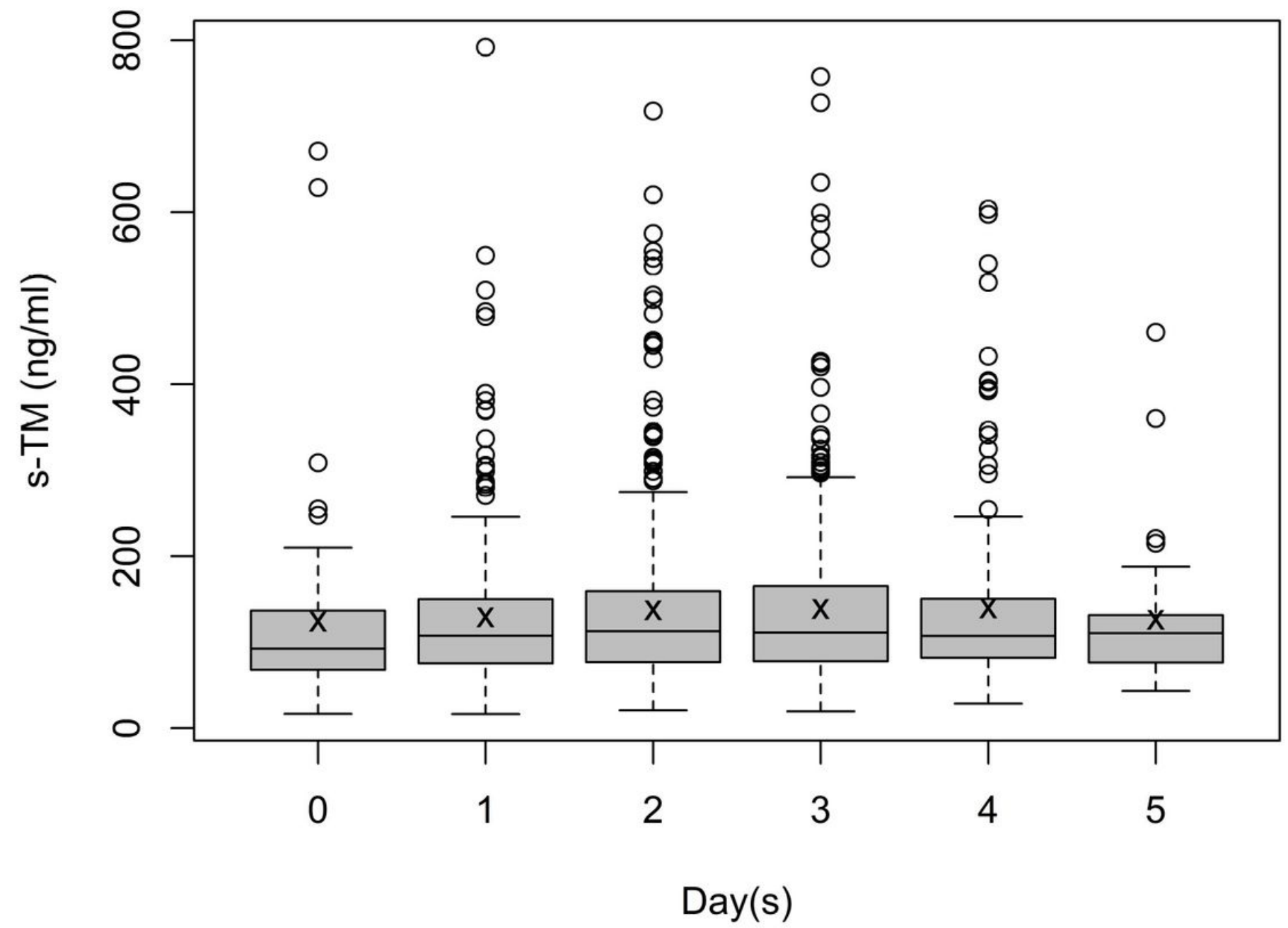

Figure 1

Box plot representing distribution of daily sTM values collected for each patient. Mean for each day is represented by ' $x$ ', outliers are represented by an open circle. Number ( $n$ ) for individual days is as follows: 56 on day 0,134 on day 1,167 on day 2,118 on day 3,45 on day 4,4 on day 5 . 


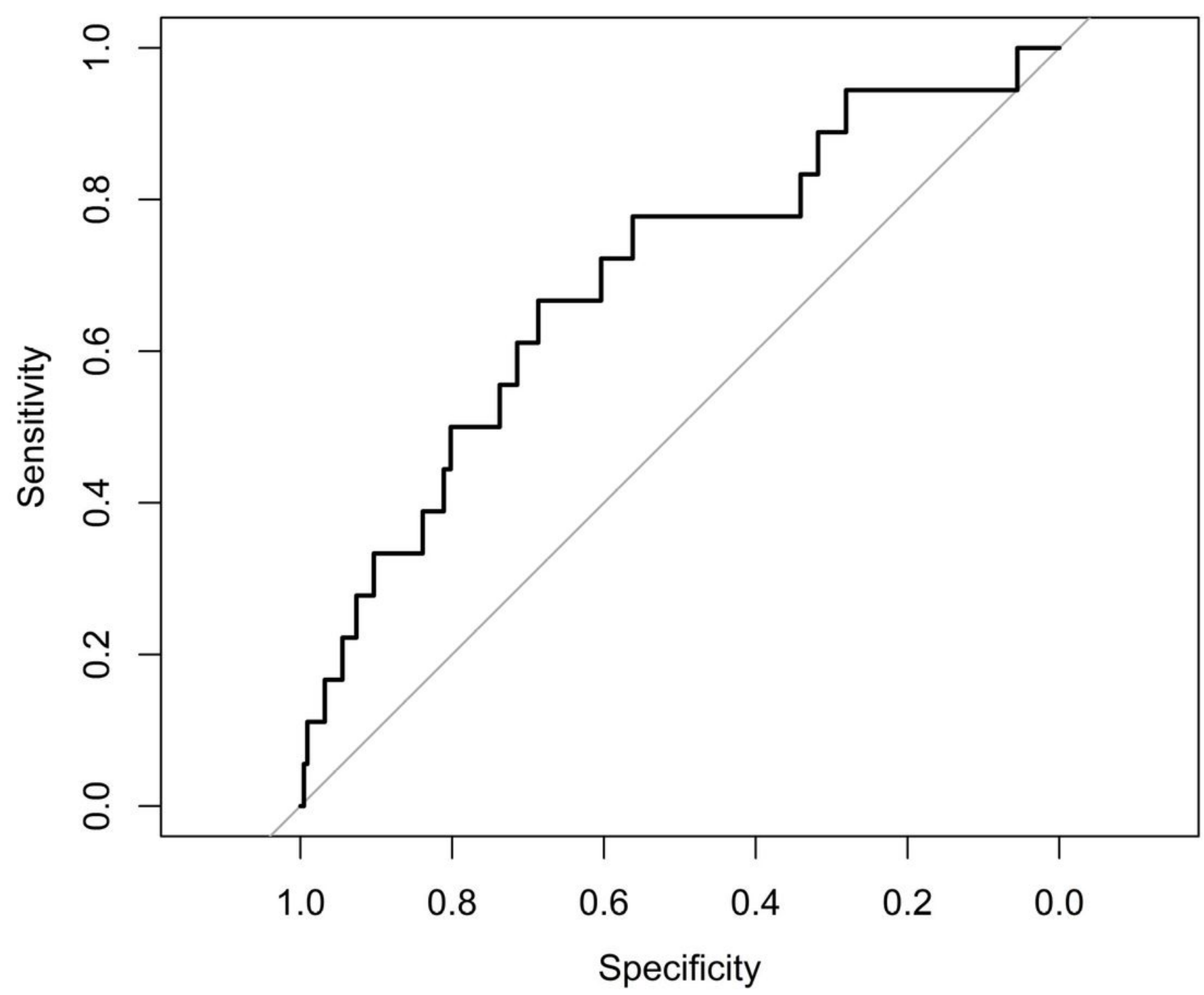

Figure 2

Receiver operating curve for the odds ratio of mortality based on STM measured at day 1. n=233.

\section{Supplementary Files}

This is a list of supplementary files associated with this preprint. Click to download.

- Suppfigs.pdf

- Supplementalmethodstablesandlegends.docx 